\title{
Classroom Teaching Strategy under the Background of Situational Teaching: The Application of Jilin Li's Situational Teaching in Basic English Teaching
}

\author{
Hongqing Zhu, ${ }^{1}$ Caimin $\mathrm{Li}^{2},{ }^{2}$ Fangmei $\mathrm{Li}^{3}$ \\ 1. The 96th Middle School, Zhengzhou, China \\ 2. NENU Ideal Software Co., Ltd, Jilin, China \\ 3. Nanjing Institute of Dianji Psychological Education, Nanjing, China
}

\begin{abstract}
Jilin Li's concept of situational teaching creatively combines students' activities in both emotion and cognition, greatly mobilizes students' enthusiasm for learning, and explores an effective path for students' happy and efficient learning. Based on Li's theory of situational teaching, we created a real language teaching environment as much as possible allowing students to understand the information and language materials expressed by the situation in the process of experiencing the situation, focusing on how to study effectively in the English class. The situational teaching method is used to stimulate students' interest in English learning and to cultivate students' independent creativity, so that they can master the four basic language skills of listening, speaking, reading and writing, and finally form comprehensive language application ability.
\end{abstract}

Sci Insigt Edu Front 2019; 3(2):297-310.

Doi: 10.15354/sief.19.ar092

Keywords: Jilin Li; Situational Teaching; English Teaching; Student Development

\footnotetext{
About the authors: Hongqing Zhu, The 96th Middle School, Zhengzhou, Henan, China. Email: 272658796@qq.com.

Fangmei Li, Nanjing Institute of Dianji Psychological Education, Nanjing, China. Email: 1037576462@qq.com.

Correspondence to: Caimin Li, Research Fellow of NENU Ideal Software Co., Ltd, Jilin, China. E-mail:461772238@qq.com.
}

Conflict of Interests: None. 
INCE 1978, Chinese elementary school teacher Jilin Li has devoted herself to the study of situational teaching. In the past four decades, she has continuously summarized and finally formed a situational teaching system in teaching practice. Situational teaching is a teaching mode that makes full use of the image, creates typical scenes, stimulates students' learning emotions, and combines cognitive activities with emotional activities (Li, 2007). Situational teaching started with the reform of Chinese teaching and explores the teaching mode that combines the activities of both cognition and emotion. Her teaching and educational exploration has achieved great success. The educational process and the vivid experience of the teaching process and the ideas she embodied are precisely the responses to the confusion and crisis in contemporary education. It possesses distinct characteristics of the times (Zhu, 1999). At present, this system has not only been widely used by Chinese educators, but has also received attention internationally.

Jilin Li considered that situational teaching should pursue "formality", "sentimentality", "intentionality", and "rationality"; it emphasizes "beauty" as the boundary, "emotion" as the link, "thinking" as the core, "children's activity" as the path, and "the surrounding world" as the source (Li, 2003). Jilin Li's teaching system provides a theoretical and practical basis for Chinese teachers to carry out the situational teaching. We hereby started with English class practice and explored the application of situational teaching in basic English teaching through a large sum of relevant literatures.

\section{Research Status of Situational Teaching}

The concept of situational teaching created by Jilin Li was originally from Chinese language, but it did not stop over there. Instead, it raised the discipline-specific rules of children's learning explored in the practice of Chinese contextual teaching to be a general law applicable to other subjects, and proposed the "five elements" of children's development: 1) taking the premise of cultivating interest, inducing initiative; 2) based on guiding observation, strengthening sensibility; 3) taking development thinking as the core and focusing on creativity; 4) stimulating emotion as motivation and infiltrating education; 5) using training ability as a means of practicality. Continuously, she led teachers of each subject to combine the "five elements" with the characteristics of the subject and children, and extracted individual principles of the situational teaching of each subject (Li, 2013).

\section{Research Status in Europe and America}

As an effective educational method, situational teaching has always been the focus of scholars. In the Europe and the United States, educators have carried out researches on situational teaching from both theoretical and practical aspects. The earliest application of situational teaching to practice was Socrates. Socrates used the problem situation when teaching. He advocated that students should think in the process of answering 
questions instead of giving the answers directly. His teaching method was called "Childbirth Manner". He once said, “I don't teach by knowledge, but by like childbirth to invoke knowledge happen” (Teng, 2008). In 1632, the Czech educator Comenius published The Great Teaching Theory. In the book, Comenius wrote that "everything starts from the senses" (Fu, 1979). From this we can see that Comenius had already realized that after the concrete visualization of abstract knowledge, it can stimulate students' interest in learning and thinking, and contribute to the formation of knowledge.

For situational teaching, American educator Dewey also made a positive exploration. He pointed out that "we advocate that there must be a practical scene as the beginning stage of thinking" (Wang \& Zhao, 1981). Dewey believed that the creation of teaching situations plays an important role in the education process, and he developed the theory of situational teaching further. The Soviet educator Suhomlinski paid great attention to the role of nature's situational education. He wrote in his book Dedicating the Whole Mind to Children, "I strive to do so, throughout the childhood, to make the surrounding world and nature always provide the nourishment for students' ideology with vivid images, pictures, concepts and impressions..." (Tang, 1981). In his teaching process, he strives to allow students to achieve comprehensive and healthy development while letting them be close to the nature. In the 1950s, under the efforts of Olki Lozhanov, situational teaching entered a stage of great development. His pioneer teaching method was more humanized than the traditional teaching method. He pointed out that "for the learning process, there is not only the brain, but also the body; not only the left hemisphere of the brain, but also the right hemisphere; not only the conscious activities and the unconscious ones" (Liu, 1990). In the implied teaching method, it is to use certain situations to influence students, so that the potential of students can be maximized, and their ability can be developed.

\section{Research Status in China}

Research on situational teaching in China was no that late than that of the Europe and the United States did. As early as more than 2,000 years ago, Chinese educators have begun to explore and study situational teaching. Ancient Chinese educators attached great importance to the impact of the environment on people's learning. Mencius once suggested that if you wanted a person from the Tribal State of Chu to be proficient in using the language of the neighbor state Qi, the best way was to let the person from Chu live in Qi for several years. This emphasizes the impact of the environment on people, and indicated that environment is an important part of the situational teaching. Educator Confucius in China has also put forward his own ideas for situational teaching, including "Opportunity Teaching" and "Inspiration Teaching", which emphasized that a reasonable situation should be created at the right time to inspire students to learn effectively.

Jilin Li composed the first theoretical work, Situational Experiments and Research, on the situational teaching in contemporary China, which opened up a new situation in Chinese situational teaching. At the same time, she also published Operation 
and Cases of Situational Courses and Jilin Li and Situational Teaching that provide theoretical and practical guidance for Chinese scholars. In her point of view, situational teaching has four characteristics: the image is real, the emotion is deep, the meaning is profound and the reasoning and meaning are in it. Based on Li's theory, Xiaoman Zhu put forward the soul of the situational teaching model to pursue the coordination of children's cognitive and emotional activities. It has great generality for elementary education, and is also suitable for higher education in enlightening adult education" (Zhu, 1999).

Situational education is based on emotion. "Love" is the essence of life, and "love" is also the true nature of life. As a perceptual existence of children, teachers are emotionally alive, and children's education is the first and foremost. Teacher's emotions interact with children's demands, and form a poetic and affectionate environment. This is exactly the very aesthetic situation the situational education wants to realize. In Li's book Psalm of Situational Education, she wrote (Li, 2004),

\section{I watch the mountains and see the waters \\ Elementary school is the most beautiful \\ Children are the most beloved \\ From then on, I like a farmer \\ Faithfully plowing the field \\ Constantly working \\ The land is replenished \\ And harvest continuously \\ The earth-smelling atmosphere \\ The aroma of rice \\ Seems to have a clear river flowing \\ I enjoy the idyllic purity and sweetness}

In the language of poetry, she told her love for children, talked about her deep affection for education, and expressed her joyful feeling.

From the perspective of the occurrence of learning, the meaning of sentimental situation is the ultimate reality and fundamental of life. This "love", which is the foundation, reality and return of life, bears the heavy responsibility of saving people from the machine philosophy of ignoring real value and the animal philosophy of antirationality, and is responsible for bringing people back to the reality from the distant shore. This is responsible for re-establishing order for the contradictory modern people and re-building their homeland. Li mentioned that, "Innovation is the spark of the most vivid and spiritual wisdom of human life. Even in an instant, it is brilliant; even if it is shallow, but valuable. It is related to students' learning interest and attitude, keen observation, different thinking quality, and rich spiritual world" (Li, 2001). 


\section{Create a Situation to Improve the Path of Classroom Teaching Efficiency}

The continuous development of the "new curriculum" reform puts forward new requirements for middle school English teaching. The reform emphasizes the studentcentered, student-learning ability as the core, and focuses on the learning process and learning curriculum to truly realize the education be "focusing on people". It has criticized the traditional education, but in some points it was overestimated and excessively pursuing the innovation of teaching mode, and ignored the essence of education. "Knowledge-instilling class is criticized, but it instead becomes questioning-class, acting-class, and even exaggerating-class; and the independent, cooperative exploration becomes vulgarization, flamboyant, and empty in contents" (Zhou et al, 2018).

Therefore, teachers should pay attention to the effectiveness of teaching in practice, adopt appropriate methods according to specific contents. In order to stimulate students' interest in learning, and help them actively participate in classroom teaching to meet their own development, and then improve the classroom teaching efficiency (Zhang, 2019). Therefore, the emergence of situational teaching provides teachers with an effective path for improving the ability of comprehensive language use.

\section{Taking the Initiative as the Premise of Cultivating Interest}

Learning interest is a psychological tendency for students to learn selectively and happily to approach or study certain things. Educator Confucius once said that "the person who knows is not as good as the one who is good, but the one who is good is not as good as the one who is happy". As educator Xingzhi Tao emphasized that "the combination of knowledge and practice", which all reflect the importance of interest to learning (Lu, 2015).

\section{Create Language Situations to Stimulate Students' Interest in Learning}

In traditional English teaching, "writing" is over-emphasized with less attention paid on "speaking”, which makes students' high scores but low ability. The embarrassing situation of "Dumb English" is frequent enough for teachers to reflect the phenomenon. Therefore, teachers should provide students with the opportunity to "speak" through creating a linguistic situation, and stimulate students' interest in learning, and improve their spoken ability (Yu \& Zhang, 2019). For example, in the teaching of the seventh grade of the text book Unit 10. Where Did You Go On Vacation?, teachers can create interactive situations to shape the context of the English language. First of all, teachers can ask students questions such as "Where did you go on vacation?", ask students questions randomly, encourage them to answer questions in English and give a timely feed- 
back and comments on their responses. So a simple free talk formed with students. In addition, teachers can also let students use the group as a unit to tell each other their experiences of their vacations in English. Given the group communication can easily be used by students in an open way and then enhance their confidence in English communication. In this way, via the learning topics to communicate each other and shaping the active language situation can effectively stimulate students' interest in learning.

\section{Use Body Language to Drive Students to Learn Enthusiasti- cally}

American psychologists have proved with experiments that a valid message equals to $7 \%$ of text plus $38 \%$ of vocal and $55 \%$ of facial expressions. Based on this, the body language of teachers in English instruction much easier to enable students to concentrate on the language and promote the learning efficacy. For example, when teaching a single word, the teacher can use the meaning of the word to show in an expressive body language, so that the student can understand and memorize the word easily. Like the word "amaze", the teacher can make a surprised facial expression, and even in an exaggerated expression to make it easier for students to remember the word. On this basis, we can classify the emotional words, and let students perform in groups to help them learn English in a situational event.

\section{Strengthening Susceptibility Based on Guided Observation}

Studies have shown that in people's cognitive activities, perception and experience are much more superior to understanding and memory. Because sentiment not only enables students to acquire knowledge, but also is accompanied by a profound emotional experience and the enlightenment of wisdom, so it is more rewarding and functions as a leap in awareness activities. The most striking feature of situational teaching is to emphasize the inner experience and feelings of the students themselves with certain forms of expression, such as music, pictures, and language.

\section{Use Pictures to Enhance the Feelings of the Situation}

In the creation of situational context, teachers can use some auxiliary tools, such as multimedia, pictures, videos, music, etc., to make the situation more realistic and attractive. For instance, when instructing the four seasons, due to the specificity of the contents, the teacher can select some representative pictures that can highlight all seasons to attract students, and simultaneously use multimedia to directly display to give an intuitively feel of the situation. When showing up, the teacher needs to take the opportunity to interact with the students. Teacher asks: What season is this? (Teacher shows picture of winter skiing, and let guess the season through the picture), and then students quickly answer Winter. Therefore, teachers use this method to instruct students the 
summer, autumn, and spring, and enhance the learning effect of vocabulary. Through the pictures, students directly feel the four seasons, and have a certain understanding of each season. Meanwhile, teachers then guide students to tell the activities at different seasons and activate the classroom teaching. In such kind of teaching, teachers use pictures to attract students' attention, and then ask corresponding problems, and guide students to have intuitive feelings about the seasons by scenery and activities in pictures and videos (Yang, 2017).

\section{Use Music to Create the Right Reading Atmosphere}

Music is the second language of human beings. Different music can lead people into different emotional worlds. In the English teaching process, teachers can also use music skillfully to create a different atmosphere. During the extracurricular reading, teachers can play different types of music according to the selected article, and convert the boring text contents into a music atmosphere that can be directly felt, which enables the students to intuitively feel the real atmosphere of the story and stimulates students' interest in reading.

\section{Imitate Life and Strengthen Students' Feeling}

Knowledge comes from life. When teaching knowledge that is closely related to life, we can return knowledge back to life through creating a vivid situation to let students get more realistic and strong feelings of the situation. For example, in the teaching of middle school English vocabulary about positions, the teacher can place objects in different positions and plan a peek-a-boo game. If the teacher asks where book is, students should answer based on their observations. In particular, when there are similar position nouns (such as on, over, and above), the teacher can intuitively let students feel the meaning of them (Huang, 2015).

\section{Focusing on Development Thinking and Creativity}

The stage of middle school is an essential period of the formation of students' thinking mode. How to inspire students to think independently and cultivate students' independent exploration and innovation is a critical topic. Therefore, we must change the traditional teaching mode with knowledge instillation as the core and teacher-centered mode, and create a new type of teaching relationship using situational teaching mode to stimulate students' self-directed learning, and cultivate their innovative and explorative spirit (Gan, 2017). In The Analects of Confucius, Confucius indicated that "Learning without thinking will be confused, and thinking without learning will be doubtful." emphasizes the importance of individual independent thinking and learning. Students' initiative to acquire knowledge will have a multiplier effect compared to passive acquisition. 


\section{Create a Dialogue Situation to Stimulate Students to Think}

Taking the How Often Do You Exercise? as an example, teachers can start the situational teaching mode using a dialogue, such as:

\section{A: How often do you exercise?}

$B$ : Let me see. I don't do much exercise. How often do you exercise?

A: I do exercise every day.

This type of dialogue allows students to clearly understand the theme of the text and the usage of specific sentences, and communicate freely can also invoke thinking that is conducive to the formation of English thinking (Tan, 2018).

\section{Establish an Activity Situation and Cultivate Students' Self- Creativity}

In teaching, teachers can use students' current English level and curiosity, and create an activity situation that is in line with their psychological development. Under the premise of making full use of the existing knowledge, help students to explore independently and cultivate their ability creativity.

In the Ninth Grade English, Unit 15: We're Trying To Save The Manatees!, the teacher can organize students to talk around the topic Whether To Build Zoos. First, the teacher sets up supporters and opponents based on whether the zoo should be established, and the students are free to choose the debate position. The supporting side expressed their view on "Zoos are terrible places", while the opponents express their ideas based on "Zoos are important places". Through the debate of the two viewpoints, the teacher guides the students to further understand the context of the text. Then, during the debate, the teacher consciously guides the students to learn the knowledge and abilities, such as the skill required for the debate, "Try to speak loudly and clearly", "Try to make it convincing", so that the students gradually strengthen the debate skill in the activity. For another example, the basic debating sentences like "I think that ...", "I believe that ...", "I feel that ...", "I agree/disagree with you", "Could you tell me ...?", "Why do you think ...?", "Do you think ...?", etc. After the final debate, the teacher can extend the activity to the after-school and write a dialogue with humans on his favorite little animals. Let students write down the knowledge they gained in the debate, and further enhance the students' sense of caring for animals and the responsibility to protect the environment.

A debate contest in English, from pre-event preparation to the competition and then to the final summarization, allow students to fully understand the relevant knowledge of animal protection in China and other countries in the world in the process of preparing the debate materials, and exercise positive thinking during the debate. It will enable students to deepen their sense of responsibility for animal protection and 
environmental protection in the summary of activities, "Let students consolidate textbook knowledge, and promote knowledge directly into competence.” (Li, 2012)

\section{Inspiring Emotions as a Starting Point and Infiltrat- ing into Educational Traits}

Lenin (Vladimir Ilyich Ulyanov) said, "If a person has no feelings, it is never possible for the person to pursue the truth." "People-oriented" is the educational idea of emotional teaching and the core concept of situational teaching. From the perspective of cognitive psychology, English teaching requires teachers to pay attention to emotional factors in teaching, make the teaching objectives more perfect in emotional transmission, and improve teaching quality, so as to promote students' abilities of emotional cognition and English learning to develop in an all-round way.

\section{Use Pictures to Infiltrate Teaching in Emotions}

When teaching middle school English, using pictures to create situations can make students have an intuitive feeling and enhance students' emotional awareness. For example, in teaching the Unit 4 How Do You Get To School? from the eighth grade middle English, teachers can use the means of display and guidance for emotional education. The content of this module is related to the transportations such as car, bus, metro, taxi, bike, etc. that help students to go to school, so teachers have carried out emotional education and teaching activities in traffic safety. In order to make students aware of the importance of obeying traffic rules, teachers select some common pictures of traffic accident from the internet, such as accidents caused by intentional passing the red lights, motorcycles colliding with trucks, etc., and show them using multimedia. In this way, students can understand the importance of traffic safety and remind themselves to obey the traffic rules, thus achieving the goal of emotional education.

\section{Use Fable Stories to Convey Spiritual Power in Comprehen- sion}

Teaching is both a cognitive and an emotional process. The use of fable stories in the teaching allows students to establish a correct outlook on life and values while gaining insight. For example, the story entitled Where Can You Find the Riches? tells that two farmers looking for diamonds. The first farmer had just a few acres of diamonds, but he did not know how to find out. He heard the fake news, sold his land and went to other places to find diamonds. In the end, he did not find anything and desperately committed suicide by plunging himself into the river. Whereas the other farmer accidentally possessed the most productive ore in the entire African continent after he noticed the sparkling nuggets. The story is not long, but the teacher can mark the harder words in Chinese, so that the students can understand better. In addition, teachers can retell the story 
after reading by students. By summarizing the story into a short paragraph, it can not only deepen the understanding, but also exercise the language expression. Then, the teacher can ask the students questions about the two farmers' characteristics. Finally, lead the students to understand the last paragraph together and sublimate the theme of the story, let them realize that "Each of us is, at this moment, standing in the middle of our own land of diamonds". Each of us has a huge treasure in it. As long as we have the confidence and patience to explore ourselves, we will one day be able to find all the wealth that will allow us to succeed. The final sublimation allows students to understand the importance of the self-awareness and self-discovery, while motivating students to be confident and delivering the correct spiritual power (Online English Listening Room, 2010).

It can be seen that creating a teaching scenario that can stimulate the emotional resonance of the students and achieve emotional penetration. In daily teaching, teachers can also explain and develop their English learning ability, and help students establish correct values and cultivate them into a modern youth that meets the needs of the times (Yang, 2017).

\section{Using the Ability of Training Disciplines as a Means of Prac- ticality}

As a language subject, English mainly develops students' ability to listening, speaking, reading, and writing. Therefore, in the process of English teaching, teachers should pay attention to the cultivation of these four parts, set up situations in the class, and exercise and cultivate students' abilities in the context.

\section{Use Game Interaction to Develop Students' Practical Ability}

Compared to other methods, game interaction is the most interesting way for students. The application of game activities in English teaching is extremely beneficial to the active classroom atmosphere and enriches the teaching methods. The setting of the game situation must be closely combined with the content of the class; otherwise the efficiency of the teaching activity will be reduced. Therefore, teachers should set up a game with strong operability to enrich the classroom teaching, and stimulate the students' enthusiasm for learning, so as to cultivate students' practical ability better (Sun, 2018). For example, in the Seventh Grade, Unit 7 How Much Are These Socks? When you teach, you can create a trading situation simulation game, a group of students play the seller, and another group of students play the buyer (after the end of the round, the student roles are exchanged), let them conduct inquiry and trading. This not only allows students to deepen their understanding of the text and sentence patterns in the communication, but also enables them to enhance the comprehensive application in the interaction. 


\section{Create Colorful Activities to Enhance Students' Prac- tical Ability}

In addition to situational teaching of textbook contents, English teaching requires more colorful extracurricular activities. For example, Teaching is full of fun through English language games, reading sessions, speech contests, dictation competitions, essay competitions, and listening competitions. Let students improve their interest in English learning and ability to use English by self-editing English essays, creating English tabloids and greeting cards, and even designing English personal homepages. In the PEP version of the English textbook, it not only introduces the traditional culture of China, but also pays attention to the festivals, etiquette and culture of European and American countries. Such a blend of Chinese and foreign cultures gives teachers a good opportunity for educational activities. Teachers can let students learn and introduce the small and short drama about cultural conflicts on the basis of further understanding of Chinese and foreign cultures after class. For example, Chinese people participate in the sitcoms of European and American friends. The story is written by the students themselves, and the characters can be set by the teacher or freely selected by the students. Such a sitcom not only allows students to further understand the cultural differences between China and foreign countries, but also enhances the students' comprehensive practical ability in listening, speaking, reading and writing.

\section{The Enlightenment of Jilin Li's Situational Teaching}

Situational teaching has distinct characteristics and a strong sense of the times. On the one hand, it reflects the new achievements and new ideas of China's elementary and middle education reform in the new era; on the other hand, it shows the new trend of China's education development in the 21 st century.

Situational teaching pursues the coordinated development of both cognitive and emotional activities, and achieves the purpose of promoting students' emotional development. There are several ways to achieve this goal. First, human emotional development is not a spontaneous process of physiological phenomena. Although the "focus" of emotional mobilization is on the amygdala of the limbic system of the human brain, the level of emotional quality is inseparable from the frontal lobes and their cognitive processing. Through thinking operations, the concept of words is used to find appropriate expression of emotional energy, that is, controlled expression, as thus regulating emotional activities to reflect it as a social-cultural-psychological combination. Jilin Li has summed up the relationship between them as "objects stimulate emotions, emotions stimulate words, and words promote thinking", and "thinking" deepens the understanding of "objects". We understand that "thinking" here has a certain emotional power, and is the emotion accompanied by "sentimental thinking". At this stage, emotional development and cognitive progression are inextricably linked. Second, Human emotion development has different signs from cognitive development. The core symbol is the level 
of experience - the scope, content and feeling of experience. If formalism masters a large amount of knowledge, it will inevitably cause people's feelings to shrink. However, situational teaching uses its vivid means to create aesthetically pleasing situations, thereby taking advantage of the strong appeal of the situation and preserving the susceptibility of students (Zhu, 1999).

The ideological connotation of situational teaching is rich and profound, and the operation method is concrete and effective. It has many achievements in the development of teaching reform and situational curriculum. Generally speaking, the characteristics of the era implied by this theoretical system are concentrated in three aspects.

\section{Paying Attention to Emotional Factors and Realizing the Organic Inte- gration of Educational Goals through "Cultivating People with Emo- tions"}

One of the outstanding characteristics and important contributions of situational teaching is that it re-emphasizes the long-neglected emotional factors in the proper position of education, and integrates morality, intelligence and beauty into the situation, thus realizing a real education in the teaching process. The organic integration of the "Goal of Human Education" enables students to learn to be a human being while seeking knowledge, and to form a healthy and rich spiritual world.

\section{Emphasizing Active Development, Creating a Realistic Way for Stu- dents to Live and Actively Develop through Situational Creation}

The basic focus of situational teaching is the harmony and active development of students" mind and body. The "situation" of situational teaching is essentially an artificially optimized environment, which is an environment that encourages students to move in. Situational teaching strives to place people's active participation and active development at the core. Through the students' perception, operation, experience, inquiry and discovery, they can fully and actively develop.

\section{Based on the Local, Paying Attention to Practice, Enriching the Educa- tional Theory and Practice with Chinese Characteristics}

Situational teaching is not an exotic product, but a product of Jilin Li's practical exploration in the past 30 years. This achievement has a strong local flavor and national characteristics. At the same time, this achievement is highly practical and targeted. It is gradually formed and developed in the long-term teaching practice by Jilin Li. She based her teaching theory on the practice of teaching reform with full enthusiasm and sincerity, through experiencing and understanding of the true meaning of education, and deepening rational recognition. The contribution of situational teaching is multifaceted. Not only does the achievement itself effectively enrich the educational theory and prac- 
tice with Chinese characteristics, but also the development process of it also gives a lot of enlightenment to educational researchers (Tian, 1997).

As a great child educator who came out of the ranks of teachers, Jilin $\mathrm{Li}$, as Hegel said, is precisely a "this one", a typical figure who possesses the commanding heights of history. Jilin Li has won numerous awards in her life. The rarest thing is to win the first prize of the National Basic Education Teaching Achievement Award. This is the highest award in China's basic education. General Secretary Jinping Xi personally presented her in the Great Hall of the People. Jilin Li has written numerous books. As a world-renowned publishing house specializing in academic publishing, the German Springer Publishing House purchased the copyright of her work and published it worldwide. There is still no second among all elementary and middle school teachers to date.

\section{References}

Comenius, Fu R. (1979) Big Teaching Theory. Beijing: People's Education Press, 65.

Gan S. (2017) Creating situational teaching and cultivating students' innovative learning consciousness. Qinghai Edu, (12):50.

Huang R. (2015) Discussion on the teaching of English vocabulary in junior middle school. Chengcaizhilu, (06):90.

Li J. (2001) The soul of education: cultivating students' innovative spirit. People Edu, (09): 50-53.

Li J. (2003) Primary school Chinese situational teaching: Li Jilin's conversation with young teachers. Beijing: People's Education Press, 5, 17, 359.

Li J. (2004) Psalm of situational education. Beijing: Higher Education Press, 105.

Li J. (2007) Li Jilin's Anthology. Volume One. Beijing: People's Education Press, 5.

Li J. (2013) Trilogy of Situational Education (Volume 2 of Skylark - Documentary:
Expansion of Situational Education). Beijing: Educational Science Press, 25.

Li X. (2012) The application of classroom debate in junior middle school English teaching. Teach Month (2nd Ed), (09): 21-23.

Liu S. (1990) Teaching Method Encyclopedia. Beijing: Economic Publishing House, 404.

Lu X. (2015) On the cultivation of practical ability of junior high school students. Chongqing: Southwest University.

Online English Listening Room (2010) Where Can You Find the Riches. http://www.tingroom.com/maillist/2010/2 02/125630.html, 12.11.

Suhomlinski. Tang Nianci translated. (1981) dedicated the whole soul to children $[\mathrm{M}]$. Tianjin: Tianjin People's Publishing House, 157.

Sun P. (2018) Wonderful introduction, activation of the classroom - analysis of junior 
high school English pre-class introduction teaching strategy. Acad Week, (33): 85-86.

Tan X. (2018) How to improve the effectiveness of junior middle school english classroom teaching under the new curriculum reform. J Multimedia Network Teach (China), (03):122.

Teng F. (2008) Application of Socratic teaching method in law teaching. Jilin Econ Manag Cadre Coll Rep, 2(1): 102.

Tian H. (1999) Situational Teaching: The Characteristics and Significance of Situational Education. Cours Teach Mat Teach Meth, (07): 18-21.

Wang C., Zhao X. (1981) Dewey Education Theory. Shanghai: East China Normal University Press, 180.

Yang C. (2017) Focus on emotional penetration passing positive teaching energy. Master Online, (09): 69-70.
Yu W., Zhang J. (2019) How to realize the teaching of junior middle school English fun. Chin Rural Edu, (20):169.

Zhang X. (2019) The Status quo and countermeasures of junior middle school english teaching under the background of new curriculum. Gansu Edu, (13):129.

Zhou Y., Liang Q., Luo D., Zhou Y., Li H., Huang C. (2018). Solutions to classroom teaching problems in primary and middle schools. Research on the development of teachers' teaching ability (Guangxi Provincial General Research Group) (13): $931-935$.

Zhu X. (1999) Situational education and human emotional quality. Cours Teach Mat Teach Meth, (01): 8-10.

Received: 10 July 2019

Revised: 29 July 2019

Accepted: 07 August 2019 